Agron. Mesoam. 29(2):343-362. Mayo-agosto, 2018

ISSN 2215-3608, doi:10.15517/ma.v29i2.29107

http://www.revistas.ucr.ac.cr/index.php/agromeso

\title{
Comportamiento agronómico y productivo de nuevas variedades de Cenchrus purpureus tolerantes a la sequía ${ }^{1}$
}

\section{Agronomic and productive performance of new drought tolerant Cenchrus purpureus cultivars}

\author{
José Leonardo Ledea-Rodríguez ${ }^{2}$, Jorge Valentín Ray-Ramírez², Ramón Crucito Arias-Pérez², \\ José Marcelino Cruz-Tejeda2, Giselle Rosell-Alonso², Juan José Reyes-Pérez $z^{3,4}$
}

\begin{abstract}
Resumen
La productividad de los pastos y forraje se ve cada vez más limitada por la variabilidad del clima y los prolongados tiempos de sequía, por lo que, es necesario introducir plantas que presenten tolerancia, y sean productivas en condiciones de sequía estacional. El objetivo de este trabajo fue caracterizar el comportamiento agronómico y productivo de nuevas variedades de Cenchrus purpureus tolerantes a la sequía. Se emplearon tres variedades (CT601, CT-603 y CT-605) en diferentes edades de rebrote (60, 80, 100 y 120 días), en dos periodos climáticos: lluviosa y poco lluviosa de 2013 a 2014 en un ecosistema representativo del Valle del Cauto, Cuba. Las variedades estaban establecidas en un Vertisol y se fertilizaron con abono orgánico a razón de 25 t/ha. Se evaluaron algunas variables agronómicas y rendimiento de materia seca (MS) (t/ha) en condiciones de secano. Se empleó un diseño de bloques al azar con arreglo factorial, y su interacción $(3 \times 4 \times 2)$. El rendimiento de MS fue afectado por la interacción de segundo grado, el mejor promedio ( $\mathrm{p} \leq 0,001)$ lo alcanzó el CT-605 en la época de lluvias a la edad de 120 días, en la época de pocas precipitaciones se destacaron $(\mathrm{p} \leq 0,001)$ las variedades CT-603 y CT-605. El efecto de la interacción variedad con época/clima afectó significativamente $(\mathrm{p} \leq 0,001)$ la longitud de las hojas a favor del CT-601 en la época lluviosa. El CT-605 incrementó $(\mathrm{p} \leq 0,001)$ el porcentaje de hojas y tallos verdes en la estación de lluvias, en la época seca se igualaron los superíndices. Las variedades mostraron un aceptable rendimiento de MS en la época de pocas lluvias, los cambios en la morfología no afectaron el desarrollo ni su productividad.
\end{abstract}

Palabras claves: rendimiento de cultivos, Pennisetum purpureum, adaptación fisiológica, plantas forrajeras.

\begin{abstract}
The productivity of pastures and forage is increasingly limited due to climate variability and prolonged drought periods. For that reason, it is necessary to cultivate plants that are tolerant and productive under conditionsof seasonal drought. The objective of this work was to characterize the agronomic and productive performance of new drought tolerant Cenchrus purpureus cultivars. Three cultivars (CT-601, CT-603, and CT-605) were used at different regrowth
\end{abstract}

1 Recibido: 5 de julio, 2017. Aceptado: 23 de noviembre, 2017. Este trabajo formó parte de los resultados del proyecto "Rehabilitación de sistemas pastoriles de la región oriental cubana", incluido en el programa nacional de producción de alimento animal de la República de Cuba.

2 Instituto de Investigaciones Agropecuarias “Jorge Dimitrov”. Estación Experimental de Pastos y Forrajes, km 101/2, Carretera Bayamo-Tunas.Bayamo,Granma, Cuba. ledea1017@gmail.com; jvray2011@gmail.com; rarias@dimitrov.cu; tejeda@dimitrov.cu; grosell@dimitrov.cu

3 Universidad Técnica de Cotopaxi. Extensión La Maná. Av. Los Almendros y Pujilí, Edificio Universitario, La Maná, Ecuador.

4 Universidad Técnica Estatal de Quevedo. Av. Walter Andrade. Km 1 1⁄2 vía a Santo Domingo. Quevedo, Los Ríos, Ecuador. jjreyesp1981@ gmail.com 
ages $(60,80,100$, and 120 days) in two climatic periods: rainfall and low rainfall from 2013 to 2014 in a representative ecosystem of Cauto Valley, Cuba. The cultivars were grown on Vertisol and were fertilized with organic fertilizer at a rate of $25 \mathrm{t} / \mathrm{ha}$. Some agronomic variables and dry matter (DM) yield (t/ha) were evaluated under rainfed conditions. A randomized block design with factorial arrangement and its interaction $(3 \times 4 \times 2)$ was used. DM yield was affected by the the second order interaction, during the period of rainfall, CT-605 at the age of 120 days reached the best average $(\mathrm{p} \leq 0.001)$ and during the period of low rainfall, CT-603 and CT-605 were highlighted $(\mathrm{p} \leq 0.001)$. Weatherseason interaction on cultivars had a significantly positive impact $(\mathrm{p} \leq 0.001)$ on the length of leaves of CT-601 in the period of rainfall. CT-605 increased $(\mathrm{p} \leq 0.001)$ the percentage of leaves and green stems in the period of rainfall, superscripts were equalized in the dry season. Cultivars showed an acceptable DM yield during the low rainfall period, morphological changes neather affected the development nor the productivity.

Keywords: crop yield, Pennisetum purpureum, physiological adaptation, forage crops.

\section{Introducción}

En la región climática, donde está enmarcado el archipiélago cubano se presentan dos períodos, lluvioso (PLL) y poco lluvioso (PPLL), el primero se concentra entre mayo y agosto (ONEI, 2014), y el segundo en los meses restantes, donde se manifiestan prolongados intervalos entre precipitaciones, existiendo el riesgo de presentación de sequía en toda la región. Además, las temporadas de lluvias son cada vez más cortas y con reducción en las precipitaciones, por lo que, es necesario la obtención o introducción de germoplasma tolerante y que sea capaz de producir en condiciones de sequía.

En Cuba, el promedio de las precipitaciones anuales en el 2015 fue de 1180,8 mm; en la estación de pocas precipitaciones (noviembre-abril), solo llueve entre 20 y 30\% del total anual (ONEI, 2015), lo cual contribuye a un desbalance productivo de los cultivos en el año (Ramírez, 2010; Cruz et al., 2017; Ledea et al., 2017). Los pastos y forrajes son cultivos que se afectan con el comportamiento y distribución de las precipitaciones durante el año (Arias, 2012, Ledea, 2016; Ray et al., 2016).

Con el objetivo de estabilizar la producción de forrajes en Cuba, sobre todo en la estación de pocas precipitaciones, se comenzó en la década del 2000 el programa de obtención de cultivares de Pennisetum purpureus con tolerancia a la sequía, a partir del CT-115 (Herrera et al., 1993). Como resultado se obtuvieron clones tolerantes a la sequía. Al realizar la caracterización molecular de estas plantas, mediante determinación electroforética, Herrera (2000) demostró que eran variedades, y se reafirmó al mantenerse sus características iniciales por más de cinco generaciones. Posteriormente, se demostró mediante el uso de técnicas morfológicas, atómicas y combinaciones, que el género Cenchrus abarca a los géneros Pennisetum y Odontelytrum (Chemisquy et al., 2010).

Estas nuevas variedades de Cenchrus purpureus tolerantes a la sequía han sido evaluadas en la región oriental de Cuba, en ecosistemas degradados por la intensa sequía estacional (Arias, 2012; Ray et al., 2016) y en condiciones de pre-montaña (Almaguer, 2012). Estos autores coincidieron en que las variedades CT-601, CT-603 y CT-605 han mostrado una respuesta agronómica superior a la de su progenitor (CT-115).

El objetivo de este trabajo fue caracterizar el comportamiento agronómico y productivo de nuevas variedades de C.purpureus, tolerantes a la sequía. 


\section{Materiales y métodos}

\section{Localidad, clima y suelo}

El estudio se llevó a cabo durante los periodos lluvioso (PLL) y poco lluvioso (PPLL), desde abril de 2013 a abril de 2014, en la Estación Experimental de Pastos y Forrajes del Instituto de Investigaciones Agropecuarias “Jorge Dimitrov" en la provincia Granma, Cuba; situada en los $20^{\circ} 18^{\prime} 13$ " de latitud norte y los $76^{\circ} 39^{\prime} 48^{\prime}$ de longitud oeste.

La región se clasifica como tropical relativamente húmeda (Barranco y Díaz, 1989). Con temperatura media del aire entre 24,2 (PPLL) y $27,7^{\circ} \mathrm{C}$ (PLL), con valores máximos de 28,6 (PPLL) y $32,8^{\circ} \mathrm{C}$ (PLL) (Díaz, 2007). Las precipitaciones medias fluctuaron entre 256 y 248,6 mm, para el año 2013 hasta abril de 2014. En la Figura 1 se muestra el comportamiento de las precipitaciones climáticas durante la fase de experimentación.

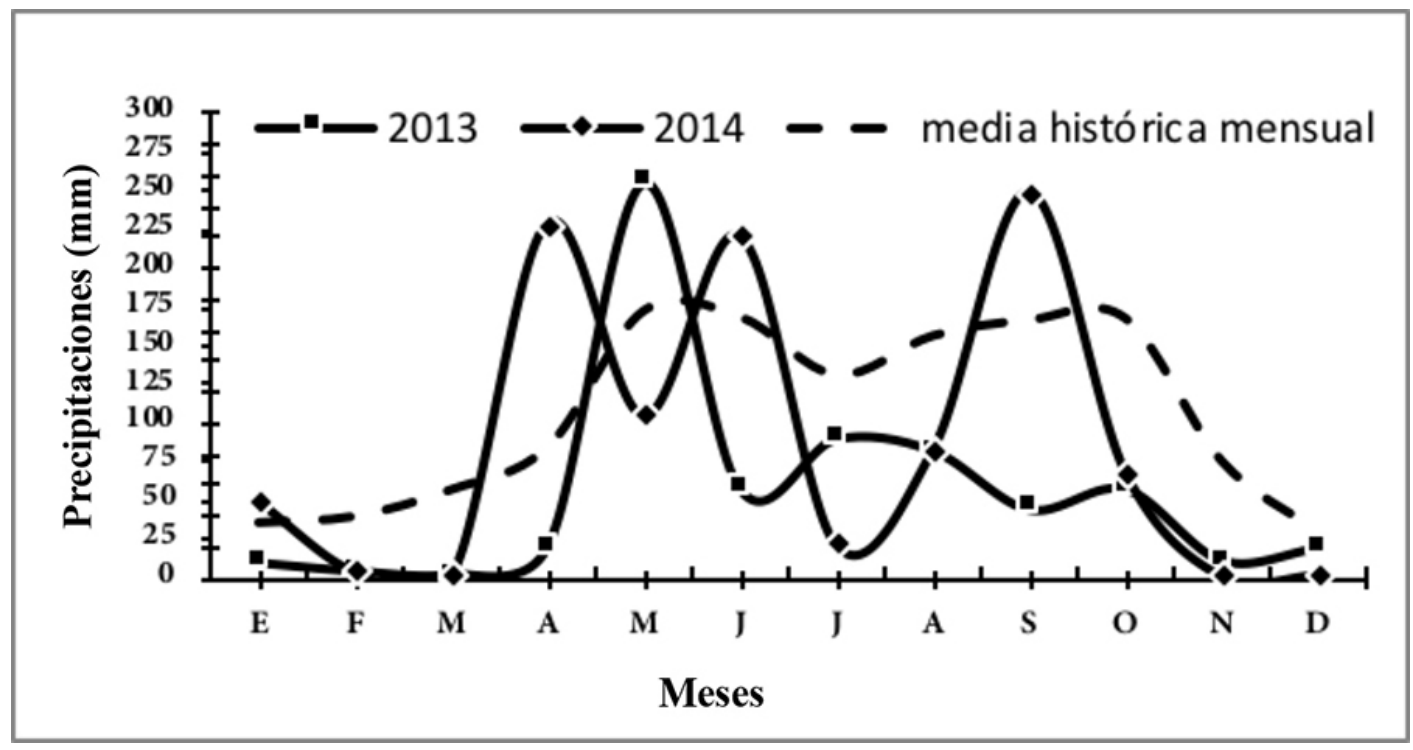

Figura 1. Distribución de las precipitaciones respecto a la media histórica mensual durante la fase experimental, donde se evaluó el efecto combinado de la variedad, estación climática y edad de rebrote en el rendimiento de nuevas variedades de Cenchrus purpureus, en la Estación Experimental de Pastos y Forrajes del Instituto de Investigaciones Agropecuaria "Jorge Dimitrov", provincia Granma, Cuba. 2013-2014.

Figure 1. Distribution of rainfall in relation to the historical monthly mean during the experimental phase where the combined effect of cultivar, the climatic period, and the regrowth age on the yield of new cultivars of Cenchrus purpureus, was evaluated at the Experimental Pasture and Forage Station of the Institute of Agricultural Research "Jorge Dimitrov", Granma, Cuba. 2013-2014.

\section{Características del suelo}

El suelo presente en el área experimental fue del tipo Vertisol (Hernández et al., 2015), drenaje deficiente, topografía llana, fertilidad media, pH bajo (débilmente alcalino), con disponibilidad general de nutrientes bajo la capa superior (Cuadro 1). Los análisis químicos de suelo se desarrollaron en la dirección provincial de suelos y fertilizantes de Granma. 
Cuadro 1. Composición química del suelo en el área experimental antes de la fertilización. Granma, Cuba. 2013-2014.

Table 1. Chemical composition of soil in the experimental area before fertilization. Granma, Cuba. 2013-2014.

\begin{tabular}{|c|c|c|c|c|c|c|c|c|c|}
\hline \multirow[b]{2}{*}{ pH KCl } & \multirow[b]{2}{*}{ pH $\mathrm{H}_{2} \mathrm{O}$} & \multicolumn{4}{|c|}{$\begin{array}{c}\text { Disponibles } \\
\text { mg/100g de suelo }\end{array}$} & \multicolumn{4}{|c|}{$\begin{array}{c}\text { Asimilables } \\
\text { cmol/kg de suelo }\end{array}$} \\
\hline & & $\mathbf{P}_{2} \mathbf{O}_{5}$ & $\mathbf{K}_{2} \mathbf{O}$ & \% M.O & $\% \mathrm{SST}$ & $\mathrm{Ca}$ & $\mathbf{K}$ & Mg & $\mathrm{Na}$ \\
\hline 5,18 & 6,90 & 2,21 & 8,33 & 1,90 & 0,0488 & 13,2 & 0,218 & 7,4 & 0,8 \\
\hline
\end{tabular}

\%MO: materia orgánica/organic matter; \%SST: sólidos solubles totales/total soluble solids.

\section{Material vegetal utilizado}

El material vegetal para el establecimiento de las parcelas fue proporcionado por el departamento de Pastos y Forrajes del Instituto de Ciencia Animal, se utilizaron para el estudio las variedades CT-601, CT-603 y CT-605, obtenidas por cultivos de tejidos a partir del CT-115, las cuales poseen seis años de establecidas en parcelas de 200 $\mathrm{m}^{2}$, con $0,75 \mathrm{~m}$ entre plantas y $1 \mathrm{~m}$ entre surcos.

\section{Tratamiento, diseño y análisis estadístico}

Se utilizó un diseño de bloques al azar con arreglo factorial y cuatro repeticiones. Se realizaron análisis de varianza en los que se controlaron los efectos de edad de rebrote (4), variedad (3), estación climática (2) y su interacción ( 4 x 3 x 2), con un total de veinticuatro tratamientos. Para la distribución normal de los datos se empleó la prueba de Kolmogorov-Smirnov (Massey, 1951) y para la homogeneidad de varianzas la prueba de Bartlett (1937), las medias resultantes de las interacciones se compararon mediante la múltiple de Keuls (1952). El modelo matemático empleado en cada uno de los ANOVA fue el siguiente:

$\mathrm{Y}_{\mathrm{ijkl}}=\mu+\mathrm{R}_{\mathrm{i}}+\mathrm{ER}_{\mathrm{j}}+\mathrm{V}_{\mathrm{k}}+\mathrm{EC}_{1}+(\mathrm{ER} \times \mathrm{V})_{\mathrm{jk}}+(\mathrm{ER} \times \mathrm{EC})_{\mathrm{jl}}+(\mathrm{V} \times \mathrm{EC})_{\mathrm{kl}}+(\mathrm{ER} \times \mathrm{V} \times \mathrm{EC})_{\mathrm{jkl}}+\mathrm{e}_{\mathrm{ijkl}}$

$\mathrm{Y}_{\mathrm{ijk} \mathrm{l}}=$ variable respuesta.

$\mu=$ constante común para todas las observaciones.

$\mathrm{R}_{\mathrm{i}}=$ efecto de la i-ésima réplica $(\mathrm{i}=1, \ldots, 4)$.

$\mathrm{ER}_{\mathrm{j}}=$ efecto de la j-ésima edad de rebrote $(\mathrm{j}=1, \ldots, 4)$.

$\mathrm{V}_{\mathrm{k}}=$ efecto del $\mathrm{k}$-ésima variedad $(\mathrm{k}=1, \ldots, 3)$.

$\mathrm{EC}_{1}=$ efecto de la l-ésima estación climática $(\mathrm{l}=1,2)$.

$E R \times V_{j k}=$ efecto combinado de la j-ésima edad de rebrote en la k-ésima variedad.

$\mathrm{ER} \times \mathrm{EC}_{\mathrm{jl}}=$ efecto combinado de j-ésima edad de rebrote en la l-ésima estación climática.

$\mathrm{V} \mathrm{x} \mathrm{EC}_{\mathrm{kl}}=$ efecto combinado de la k-ésima variedad en la l-ésima estación climática.

ER $x \mathrm{~V} \times \mathrm{EC}_{\mathrm{jkl}}=$ efecto combinado de j-ésima edad de rebrote en la k-ésima variedad durante la l-ésima estación climática.

$\mathrm{e}_{\mathrm{ijk} \mathrm{l}}=$ error aleatorio normalmente distribuido con media cero y varianza sigma ${ }^{2}$.

\section{Procedimiento experimental}

En las parcelas se formaron subparcelas de 4,50 m lineales dentro de un surco, se utilizaron los surcos de forma intercalada coincidentes con cada edad de rebrote evaluada, cada subparcela contó con cuatro repeticiones. 
Posterior a las mediciones, se realizó el corte, para ello se eliminó el efecto de borde consistente en el surco precedente y los $50 \mathrm{~cm}$ al principio y final del surco en evaluación. Las plantas que no quedaron dentro del efecto de borde, se cortaron y pesaron, contemplándose este peso como masa verde.

Se realizó un corte de uniformidad en el mes de octubre y se le aplicó abono orgánico de origen bovino (25t/ ha) en dosis única. Para ello, se taró una carretilla y se llenó con la cantidad correspondiente en función del área y dosis de fertilizante a utilizar, y se distribuyó a lo largo del surco.

\section{Mediciones de la planta}

Las mediciones se realizaron en cinco plantas por repetición en las diferentes edades de rebrote $(60,80,100$ y 120 días), a las que se le retiraron las hojas y tallos con tijera de acero inoxidable. Se tomó en cuenta el número total de hojas verdes/planta, largo y ancho de la hoja, seleccionando la cuarta hoja para estas mediciones, según la metodología propuesta por Herrera et al. (2003). El ancho de la hoja se obtuvo a partir del promedio de las mediciones realizadas con una regla milimetrada a los segmentos base, medio y apical, mientras que, para el largo se contempló desde la base hasta el ápice; el grosor del tallo se midió en el cuarto entre nudo, según la metodología descrita por Herrera et al. (2003), utilizando un vernier (precisión de 0,05 mm).

\section{Rendimiento de MS}

Las cinco plantas que se seleccionaron para las mediciones agronómicas, se separaron en hojas y tallos, y se tomó una muestra de $300 \mathrm{~g}$ que fue secada a temperatura variable, según lo sugerido por Herrera et al. (2003). A partir del peso seco de la muestra y el peso verde de cada subparcela, se estimó el rendimiento de materia seca por hectárea.

Se realizaron tomas de muestras de suelo cada veintiún días para la determinación de la humedad del mismo, según la Norma Cubana 67:2000 a 0-20, 20-40 y 40-60 cm de profundidad, durante toda la fase experimental con la ayuda de una barrena.

\section{Resultados}

El rendimiento que alcanzó la variedad CT-605 a la edad de 120 días en la estación lluviosa, superó significativamente $(\mathrm{p} \leq 0,001)$ al rendimiento alcanzado por ella a la misma edad en la estación poco lluviosa y al resto de las variedades (Cuadro 2) en la estación lluviosa. En esta estación climática, el CT-605 a los 100 días de rebrote, no difirió significativamente $(\mathrm{p} \leq 0,001)$ de los rendimientos alcanzados por las variedades CT-601 y CT-603 a los 120 días de edad. Para las tres variedades el rendimiento se incrementó en función de la edad, independientemente de la estación climática (Cuadro 2). Sin embargo, los valores medios obtenidos por CT-601 a los 60 días en la época lluviosa coincidieron con el obtenido a los 120 días en la estación poco lluviosa, el resto de las edades difirieron entre ellas en ambas estaciones.

El rendimiento promedio de CT-603 a los 100 días en la época poco lluviosa, fue similar a los valores de 80 y 120 días en este mismo período climático, y común para los valores de rendimientos alcanzados en el PLL, el valor más deprimido $(\mathrm{p} \leq 0,001)$ con respecto al resto de los promedios se obtuvo a la edad de 60 días en el PPLL. Para la variedad CT-605, el promedio logrado a los 120 días en la época lluviosa difirió $(\mathrm{p} \leq 0,001)$ del resto de los promedios en ambas épocas climáticas, sin embargo, en el resto de las edades en ambas épocas solo fueron comunes los valores a los 60 días de rebrote

En la Figura 2 se muestra el efecto que tuvo la interacción de la edad de rebrote con variedad, sobre la cantidad de hojas por planta. Los mayores promedios se observaron a la edad de 120 días, en la variedad CT-603, este valor 
Cuadro 2. Efecto combinado de la variedad, estación climática y edad de rebrote en el rendimiento de las variedades de Cenchrus purpureus, en la Estación Experimental de Pastos y Forrajes del Instituto de Investigaciones Agropecuarias "Jorge Dimitrov", provincia Granma, Cuba. 2013-2014.

Table 2. Combined effect of cultivar, climatic season, and regrowth age on yield of Cenchrus purpureus cultivars, at the Experimental Pasture and Forage Station of the Institute of Agricultural Research "Jorge Dimitrov", Granma, Cuba. 20132014.

\begin{tabular}{|c|c|c|c|c|c|c|c|c|c|}
\hline \multirow[b]{4}{*}{ Variable } & \multirow{4}{*}{$\begin{array}{l}\text { Variedades } \\
\quad(\mathrm{CT})\end{array}$} & \multicolumn{8}{|c|}{ Estaciones climáticas } \\
\hline & & \multicolumn{4}{|c|}{ Lluviosa } & \multicolumn{4}{|c|}{ Poco Lluviosa } \\
\hline & & \multicolumn{8}{|c|}{ Edades de rebrote (días) } \\
\hline & & 60 & 80 & 100 & 120 & 60 & 80 & 100 & 120 \\
\hline \multirow{5}{*}{$\begin{array}{l}\text { Rendimiento } \\
\text { t/MS/ha }\end{array}$} & 601 & $12,2^{\mathrm{c}}$ & $20,2^{b}$ & $21,4^{\mathrm{b}}$ & $26,3^{\mathrm{b}}$ & $2,3^{\mathrm{d}}$ & $5,4^{\mathrm{d}}$ & $6,4^{\mathrm{d}}$ & $10,5^{\mathrm{c}}$ \\
\hline & 603 & $10,2^{\mathrm{c}}$ & $19,9^{\mathrm{bc}}$ & $20,4^{\mathrm{b}}$ & $26,8^{b}$ & $6,3^{\mathrm{d}}$ & $12,9^{\mathrm{c}}$ & $18,8^{\mathrm{bc}}$ & $20,3^{b}$ \\
\hline & 605 & $14,6^{\mathrm{c}}$ & $16,3^{\mathrm{c}}$ & $24,7^{\mathrm{b}}$ & $58,8^{\mathrm{a}}$ & $5,2^{\mathrm{d}}$ & $12,2^{\mathrm{c}}$ & $23,7^{\mathrm{b}}$ & $26,4^{\mathrm{b}}$ \\
\hline & $\pm \mathrm{EE}$ & \multicolumn{8}{|c|}{3,14} \\
\hline & Sig. & \multicolumn{8}{|c|}{$\mathrm{p} \leq 0,001$} \\
\hline
\end{tabular}

a,b,c,d Letra en común no difieren para $\mathrm{p} \leq 0,001$ según Keuls (1952). CT: cultivo de tejidos / Common Letters do nott differ for $\mathrm{p} \leq 0.001$ according to Keuls (1952). CT: tissue culture.

se diferenció $(\mathrm{p} \leq 0,001)$ del obtenido por CT-601 y CT-605, que mostraron valores semejantes, pero que difirieron significativamente $(\mathrm{p} \leq 0,001)$ con sus propios promedios y con los de CT-603 en las edades de 60, 80 y 100 días.

A la edad de 60 y 100 días las medias de las variedades CT-601 y CT-605, no difirieron significativamente entre sí, pero sí con los valores propios en estas mismas edades. El promedio del CT-603 fue común para CT-601 y CT-605 en ambas edades y también difirió de los valores propios.

En la longitud de la hoja (Figura 3) se observó un comportamiento uniforme en función del tiempo, y común para las tres variedades; diferenciándose solamente de forma significativa $(\mathrm{p} \leq 0,001)$ los promedios de la edad de 60 días, donde CT-601 presentó la mayor longitud y CT-605 el menor valor ( $\mathrm{p} \leq 0,001)$. Para el resto de las edades, los valores fueron similares y solo difirieron con sus promedios a los 60 días de rebrote.

Los valores significativamente superiores $(\mathrm{p} \leq 0,001)$ para el ancho de la hoja (Figura 4$)$, se obtuvieron a los 120 días de edad, y la variedad CT-605 se diferenció significativamente del resto de las variedades en todas las edades evaluadas y consigo misma en las demás evaluaciones. El valor significativamente inferior para todas las edades $(\mathrm{p} \leq 0,001)$ se obtuvo a los 100 días con CT-603, y con el del resto de las variedades en estudio. Los valores para las edad de 60 y 80 días no se diferenciaron significativamente.

Para el grosor del tallo (Figura 5), el valor significativamente superior se obtuvo a los 100 días con CT-605, comportamiento que persistió hasta los 120 días de rebrote y se asemejó al grosor del tallo del CT-603 en esta misma edad. Estos valores difieren de los promedios obtenidos en el resto de las edades de rebrote evaluadas. CT603 experimentó menor $(\mathrm{p} \leq 0,001)$ grosor del tallo a la edad de 60 días, a la vez que mostró variación con el resto de los valores a las diferentes edades.

El porcentaje de tallos (Figura 6), mostró incremento con respecto a la edad de rebrote, el valor medio superior $(\mathrm{p} \leq 0,001)$ fue para CT-605 a los 120 días de edad, seguido por CT-601 a la misma edad. Sin embargo, a los 100 días todos los valores fueron similares ( $\mathrm{p} \geq 0,05)$, y los resultados de CT-603 y CT-601 a las edades de 60 y 80 días, respectivamente, también coincidieron con los porcentajes mostrados en la edad de 100 días. CT-605 mostró el menor valor $(\mathrm{p} \leq 0,001)$ a la edad de 60 días, difiriendo con el resto de sus promedios y el de las variedades CT-601 y CT-605 en todas las edades de rebrote evaluadas. 


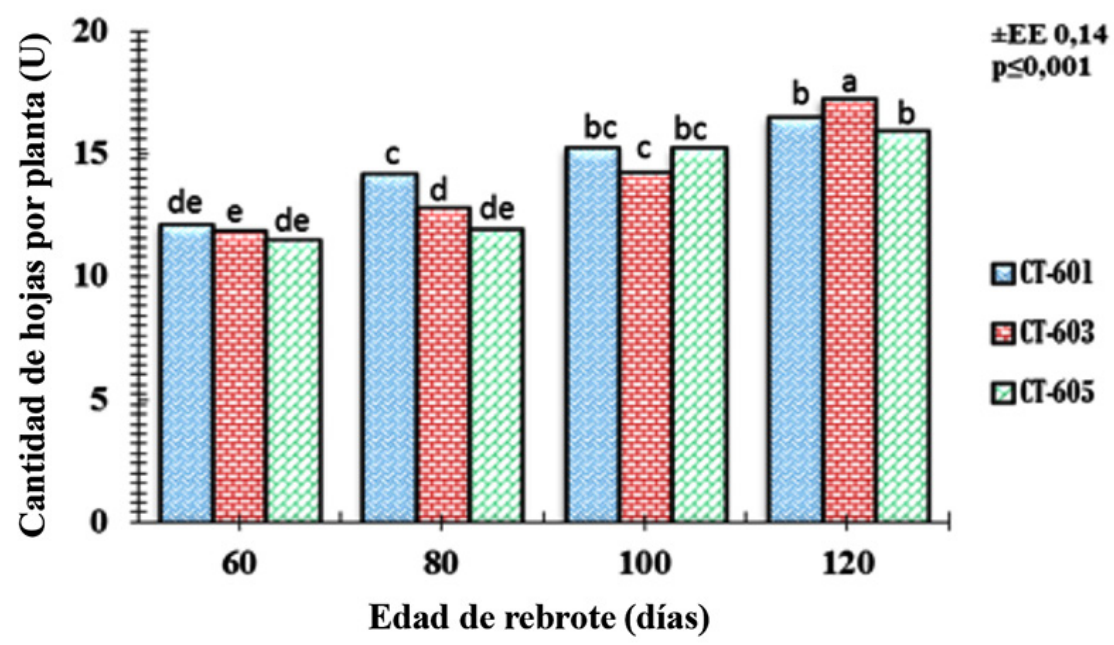

a.b.c,d.e Letras diferentes difieren para $p \leq 0,001$ según Keuls (1952).

Figura 2. Efecto en Cenchrus purpureus de la interacción variedad (CT-601, CT-603 y CT-605) con edad de rebrote en la cantidad de hojas por planta. Estación Experimental de Pastos y Forrajes del Instituto de Investigaciones Agropecuarias "Jorge Dimitrov", provincia Granma, Cuba. 2013-2014.

Figure 2. Effect of the interaction between cultivar (CT-601, CT-603 and CT-605) and regrowth age on leaves per plant of Cenchrus purpureus. Experimental Pasture and Forage Station of the Institute of Agricultural Research "Jorge Dimitrov", Granma, Cuba. 2013-2014.

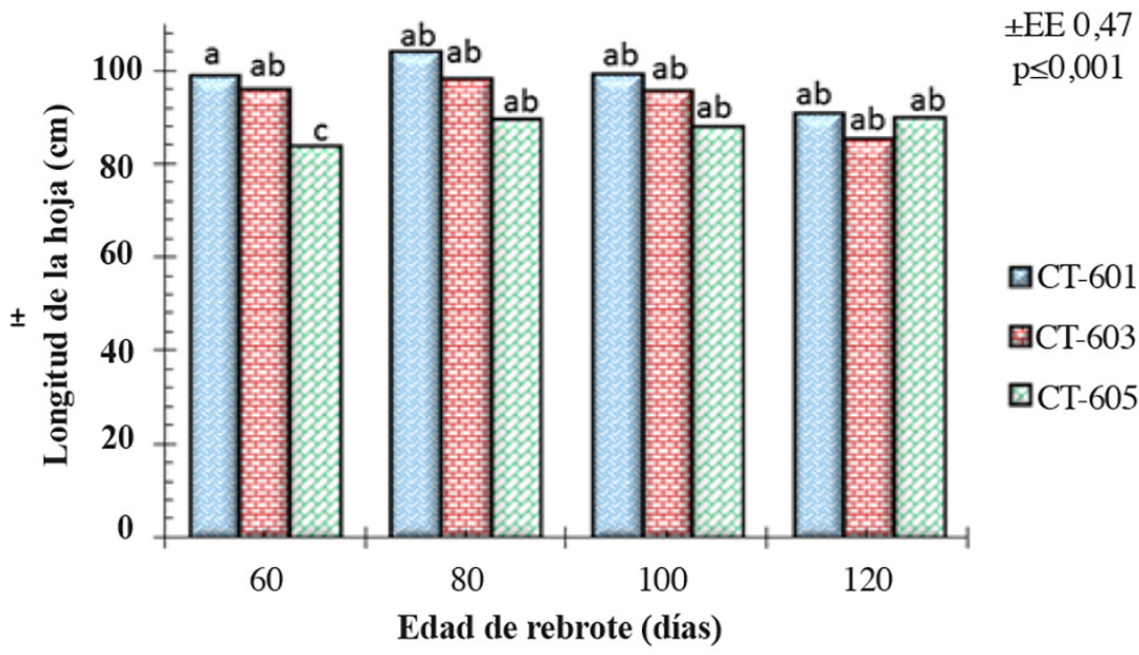

$a, b, c, d, e$ Letras diferentes difieren para $p \leq 0,001$ según Keuls (1952).

Figura 3. Efecto en Cenchrus purpureus de la interacción variedad (CT-601, CT-603 y CT-605) con la edad de rebrote en la longitud de la hoja. Estación Experimental de Pastos y Forrajes del Instituto de Investigaciones Agropecuarias "Jorge Dimitrov", provincia Granma, Cuba. 2013-2014.

Figure 3. Effect of the interaction between cultivar (CT-601, CT-603 and CT-605) and regrowth age on leaf length of Cenchrus purpureus. Experimental Pasture and Forage Station of the Institute of Agricultural Research "Jorge Dimitrov", Granma, Cuba. 2013-2014. 


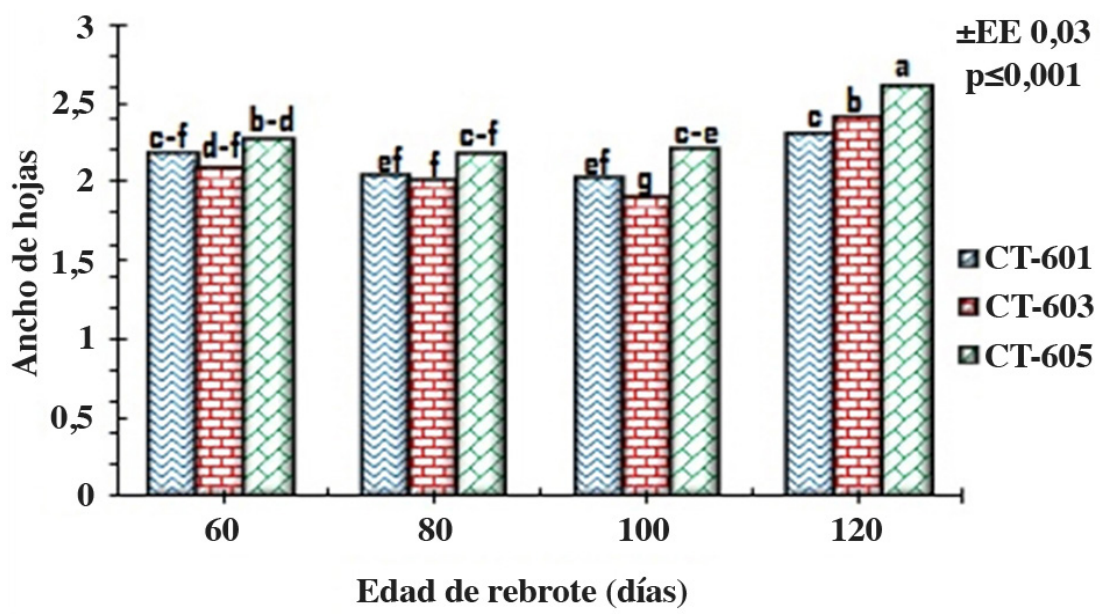

a,b,c,d,e Letras diferentes difieren para $p \leq 0,001$ según Keuls (1952).

Figura 4. Efecto en Cenchrus purpureus de la interacción variedad (CT-601, CT-603 y CT-605) con edad de rebrote en el ancho de la hoja, en la Estación Experimental de Pastos y Forrajes del Instituto de Investigaciones Agropecuarias "Jorge Dimitrov", provincia Granma, Cuba. 2013-2014.

Figure 4. Effect of the interaction between cultivar (CT-601, CT-603 and CT-605) and regrowth age on leaf width of Cenchrus purpureus. Experimental Pasture and Forage Station of the Institute of Agricultural Research "Jorge Dimitrov", Granma, Cuba. 2013-2014.

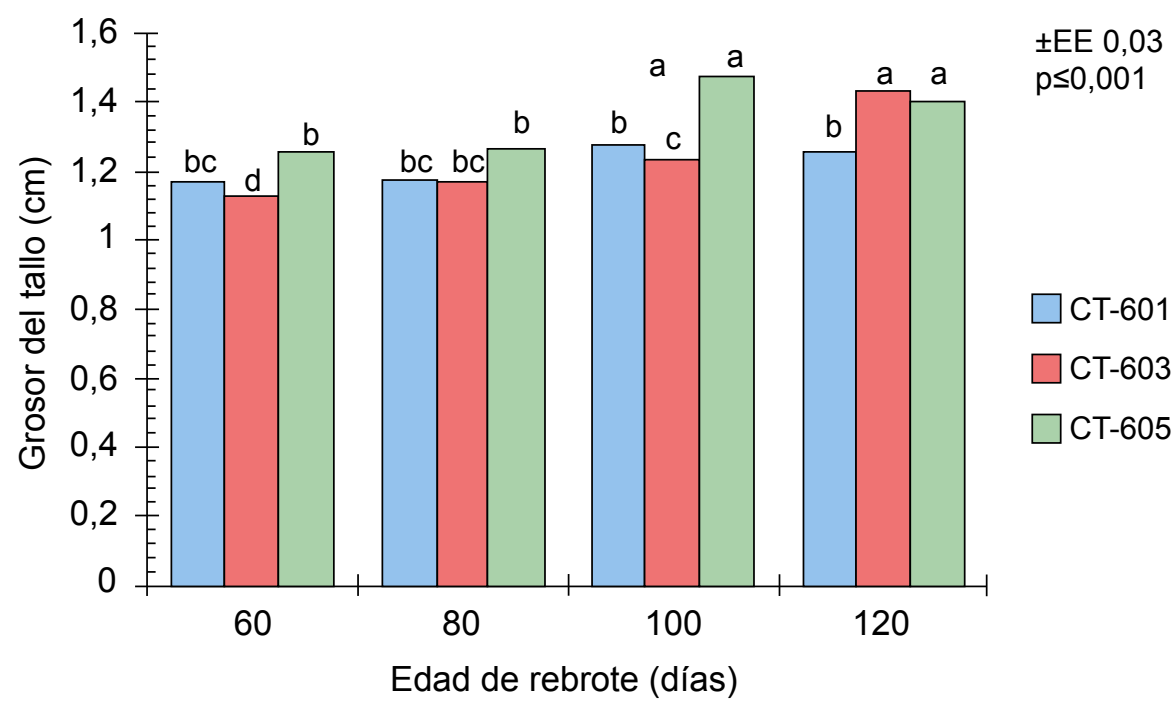

Figura 5. Efecto en Cenchrus purpureus de la interacción variedad (CT-601, CT-603 y CT-605) con edad de rebrote en el grosor del tallo. Estación Experimental de Pastos y Forrajes del Instituto de Investigaciones Agropecuarias "Jorge Dimitrov", provincia Granma, Cuba. 2013-2014.

Figure 5. Effect of the interaction between cultivar (CT-601,CT-603 and CT-605) and regrowth age on stem thickness of Cenchrus purpureus. Experimental Pasture and Forage Station of the Institute of Agricultural Research "Jorge Dimitrov", Granma, Cuba. 2013-2014. 


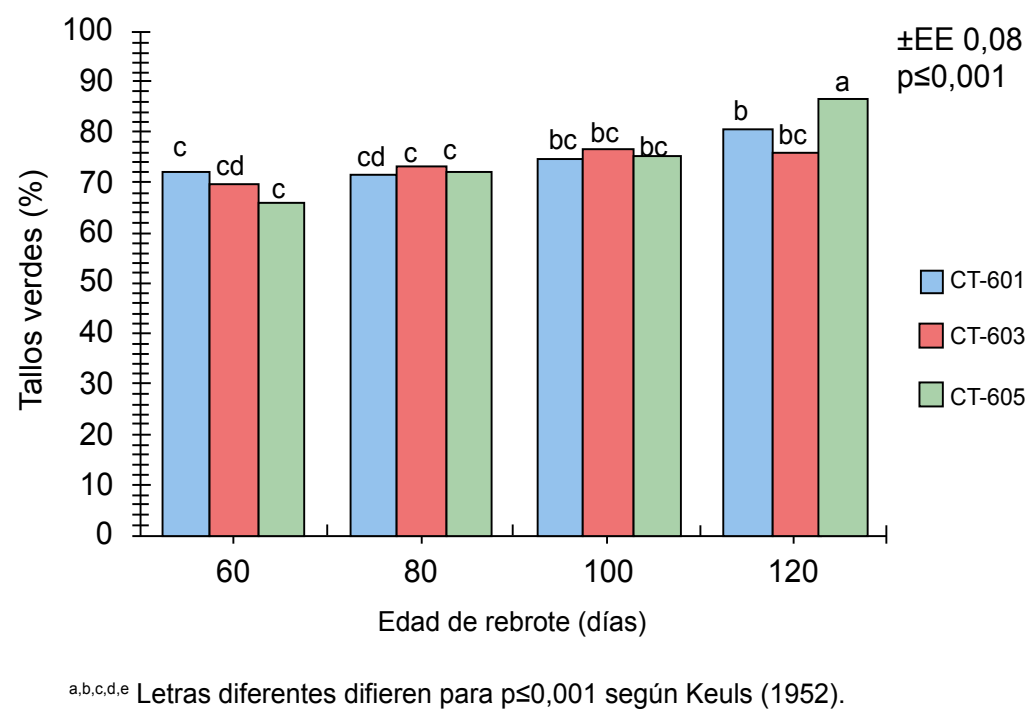

Figura 6. Efecto en Cenchrus purpureus de la interacción variedad (CT-601, CT-603 y CT-605) con edad de rebrote en el porcentaje de tallos verdes. Estación Experimental de Pastos y Forrajes del Instituto de Investigaciones Agropecuarias "Jorge Dimitrov", provincia Granma, Cuba. 2013-2014.

Figure 6. Effect of the interaction between cultivar (CT-601, CT-603 and CT-605) and regrowth age on the percentage of green stems of Cenchrus purpureus. Experimental Pasture and Forage Station of the Institute of Agricultural Research "Jorge Dimitrov", Granma province, Cuba. 2013-2014.

El porcentaje de hojas verdes (Figura 7) disminuyó conforme avanzó la edad de rebrote, pero CT-605 a los 80 y 100 días de rebrote mostró las mayores $(\mathrm{p} \leq 0,001)$ medias que, difirieron a su vez de sus promedios para las edades de 60 y 120 días, y estos últimos, no fueron comunes entre sí. El valor más bajo (p<0,001) lo presentó CT-601 a los 120 días, el cual difirió significativamente $(\mathrm{p} \leq 0,001)$ con los de CT-603 y CT-605 en todas las edades, tampoco fue común a los valores de sí mismo en las demás edades.

El efecto de la interacción estación climática con variedad, también provocó modificaciones en el porcentaje de hojas y tallos verdes (Figuras 8 y 9). Las variedades CT-601 y CT-603 tuvieron un comportamiento similar en lo referente al acúmulo de hojas y tallos en ambas estaciones climáticas, estos resultados difirieron $(\mathrm{p} \leq 0,001)$ con los valores de CT-605 en ambos periodos. En el porcentaje de hojas verdes de CT-605 en las lluvias, presentó el mayor $(\mathrm{p} \leq 0,001)$ valor para esta variable. Sin embargo, el promedio en la estación poco lluviosa no difirió del manifestado por las variedades en estudio, pero sí fue diferente $(\mathrm{p} \leq 0,001)$ del valor obtenido en la lluvia por esta misma variedad (CT-605).

Para los tallos se acumuló mayor porcentaje que para las hojas, y ocurrió un comportamiento semejante al que se describió para el efecto de la interacción en el porcentaje de hojas verdes, solo que, para la estación de pocas lluvias, CT-605 presentó el menor valor $(\mathrm{p} \leq 0,001)$, el cual difirió del promedio obtenido en las lluvias por esta misma variedad y con el resto de los promedios en ambas estaciones climáticas. El promedio obtenido en las lluvias por CT-605, fue significativamente superior al resto de los valores aportados por las variedades CT-601 y CT-603 en las dos estaciones climáticas.

La longitud de la hoja también fue afectada por el efecto de la interacción en estudio, y se observó (Figura 10) que, el CT-601 y CT-603 mostraron los mismos superíndices en la estación lluviosa, y difirieron de sus propios promedios y de los del CT-605, quien en ambos períodos climáticos presentó los valores significativamente inferiores. 


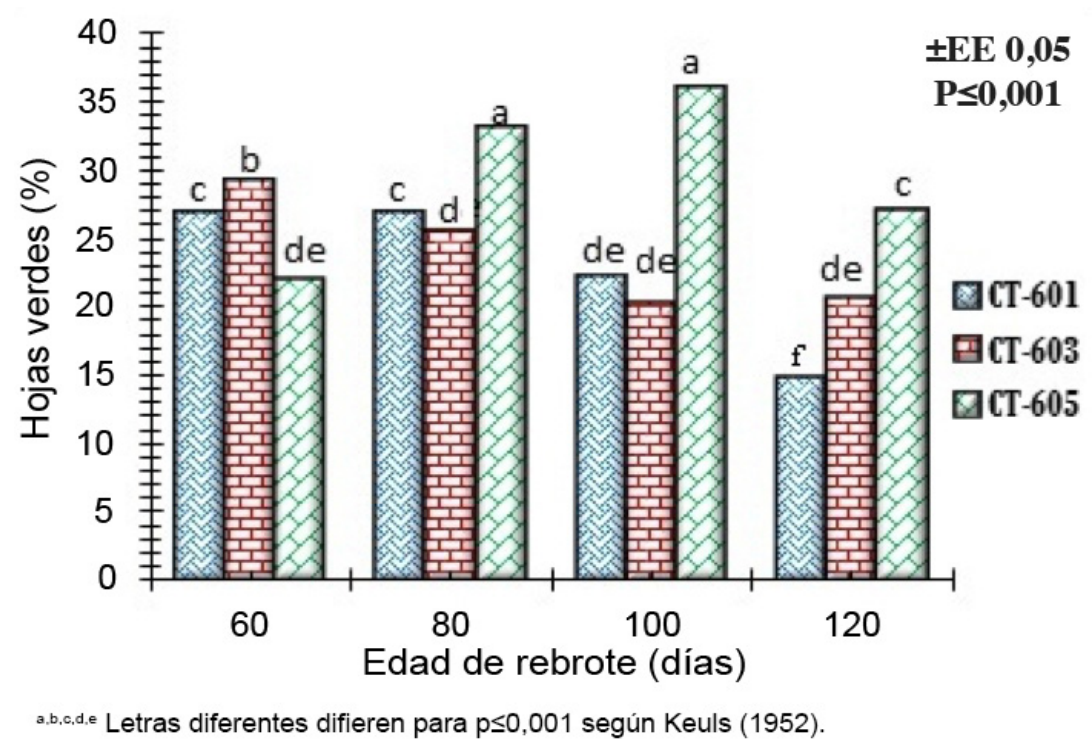

Figura 7. Efecto en Cenchrus purpureus de la interacción variedad (CT-601, CT-603 y CT-605) con edad de rebrote en el porcentaje de hojas verdes. Estación Experimental de Pastos y Forrajes del Instituto de Investigaciones Agropecuarias "Jorge Dimitrov", provincia Granma, Cuba. 2013-2014.

Figure 7. Effect of the interaction between cultivar (CT-601, CT-603 and CT-605) and regrowth age on the percentage of green leaves of Cenchrus purpureus. Experimental Pasture and Forage Station of the Institute of Agricultural Research "Jorge Dimitrov", Granma , Cuba. 2013-2014.

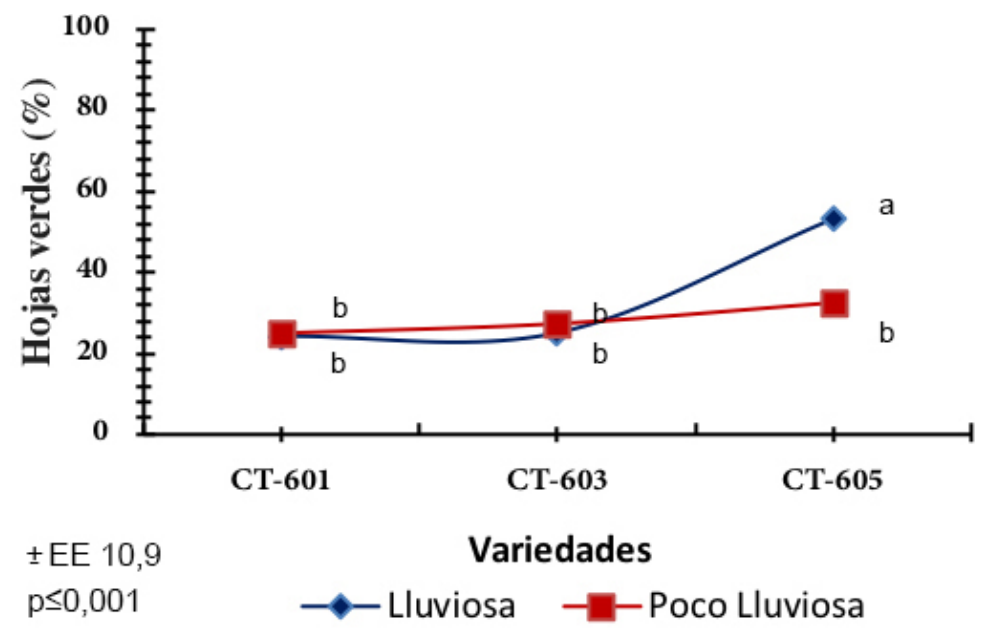

a.b.e,d.e Letras diferentes difieren para $\mathrm{p} \leq 0,001$ según Keuls (1952).

Figura 8. Efecto en Cenchrus purpureus de la interacción variedad (CT-601, CT-603 y CT-605) con época lluviosa y poco lluviosa, en porcentaje de hojas verdes. Estación Experimental de Pastos y Forrajes del Instituto de Investigaciones Agropecuarias "Jorge Dimitrov", provincia Granma, Cuba. 2013-2014.

Figure 8. Effect of the interaction among cultivar, (CT-601, CT-603 and CT-605) rainfall period, and low rainfall period on the percentage of green leaves of Cenchrus purpureus. Experimental Pasture and Forage Station of the Institute of Agricultural Research “Jorge Dimitrov”, Granma ,Cuba. 2013-2014. 


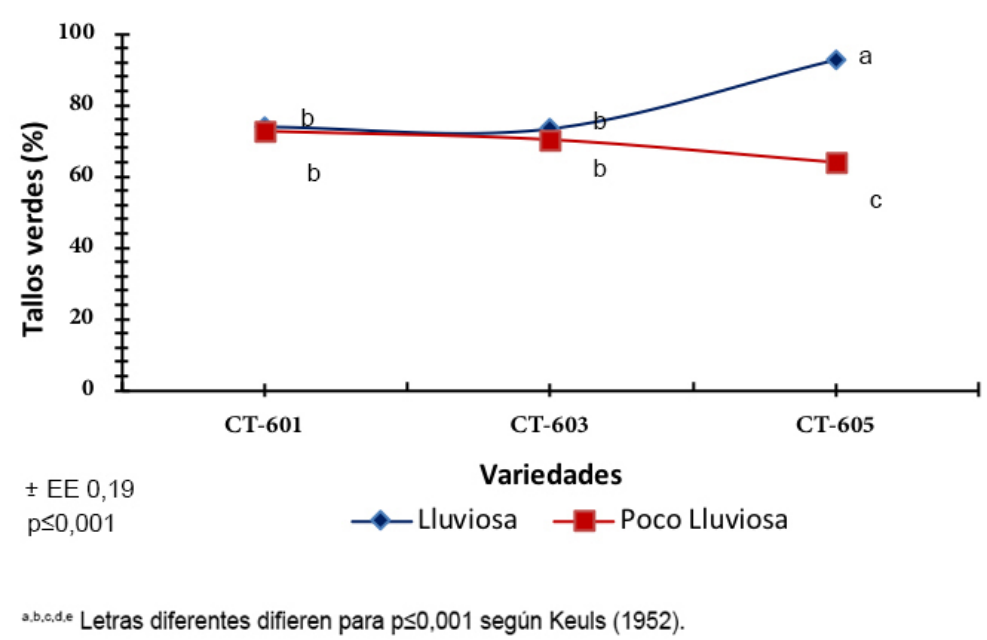

Figura 9. Efecto en Cenchrus purpureus de la interacción variedad (CT-601, CT-603 y CT-605) con época lluviosa y la poco lluviosa, en porcentaje de tallos verdes. Estación Experimental de Pastos y Forrajes del Instituto de Investigaciones Agropecuarias “Jorge Dimitrov", provincia Granma, Cuba. 2013-2014.

Figure 9. Effect of the interaction among cultivar, (CT-601, CT-603 and CT-605) rainfall period, and low rainfall period, on the percentage of green stems of Cenchrus purpureus. Experimental Pasture and Forage Station of the Institute of Agricultural Research “Jorge Dimitrov”, Granma , Cuba. 2013-2014.

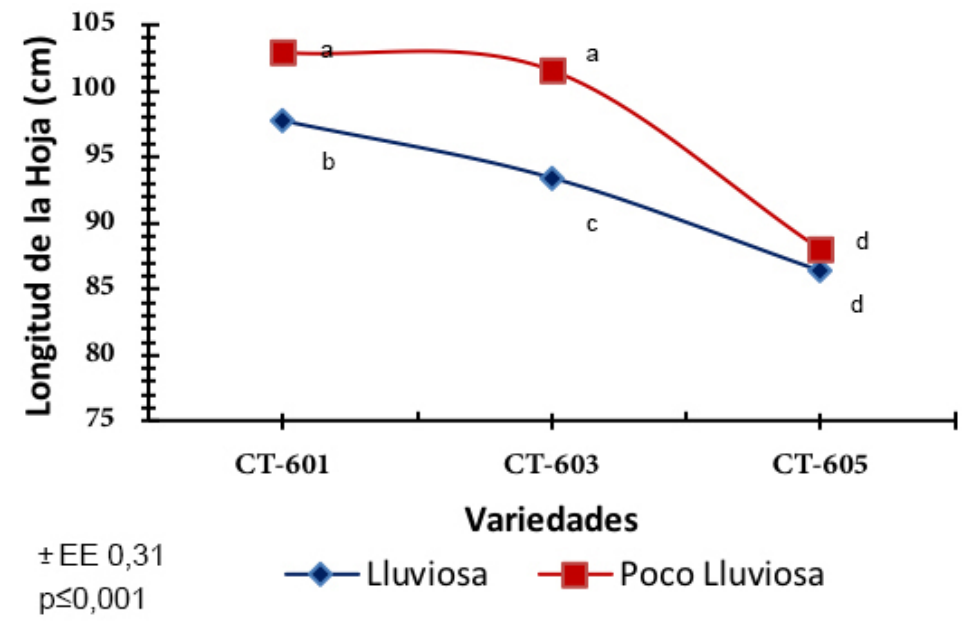

a.b.c,d,e Letras diferentes difieren para $p \leq 0,001$ según Keuls (1952).

Figura 10. Efecto en Cenchrus purpureus de la interacción variedad (CT-601, CT-603 y CT-605) con época lluviosa y la poco lluviosa, en la longitud de la hoja. Estación Experimental de Pastos y Forrajes del Instituto de Investigaciones Agropecuarias “Jorge Dimitrov", provincia Granma, Cuba. 2013-2014.

Figure 10. Effect of the interaction among cultivar, (CT-601, CT-603 and CT-605) rainfall period, and low rainfall periodon leaf length of Cenchrus purpureus. Experimental Pasture and Forage Station of the Institute of Agricultural Research "Jorge Dimitrov", Granma , Cuba. 2013-2014. 
$\mathrm{Al}$ interactuar estación climática con la edad de rebrote se afectaron varias variables agronómicas (Cuadro 3). De esta manera, el grosor de los tallos se redujo considerablemente en la época poco lluviosa, el menor registro $(\mathrm{p} \leq 0,001)$ se obtuvo a los 100 días, mientras que, los promedios de las edades 80 y 120 días fueron comunes, el comportamiento de esta variable en la época lluviosa, fue significativamente superior a la época poco lluviosa.

Cuadro 3. Efecto de la Interacción edad de rebrote con estación climática en algunas variables agronómicas de Cenchrus purpureus, variedades CT-601, CT-603 y CT-605. Estación Experimental de Pastos y Forrajes del Instituto de Investigaciones Agropecuarias "Jorge Dimitrov", provincia Granma, Cuba. 2013-2014.

Table 3. Effect of the interaction between regrowth age and climatic season on some agronomic variables of Cenchrus purpureus, CT-601, CT-603, and CT-605 cultivars . Experimental Pasture and Forage Station of the Institute of Agricultural Research "Jorge Dimitrov", Granma, Cuba. 2013-2014.

\begin{tabular}{|c|c|c|c|c|c|}
\hline \multirow[t]{2}{*}{ Variables } & \multirow{2}{*}{$\begin{array}{l}\text { Estaciones } \\
\text { climáticas }\end{array}$} & \multicolumn{4}{|c|}{ Edades } \\
\hline & & 60 & 80 & 100 & 120 \\
\hline \multirow{3}{*}{$\begin{array}{l}\text { Grosor deltallo } \\
(\mathrm{cm})\end{array}$} & Lluvia & $1,15 b$ & $1,24 \mathrm{ab}$ & $1,28 \mathrm{a}$ & $1,3 \mathrm{a}$ \\
\hline & Seca & $1,24 b$ & $1,04 d$ & $1,38 \mathrm{c}$ & $1,2 \mathrm{~d}$ \\
\hline & $\pm \mathrm{ES}$ & \multicolumn{4}{|c|}{0,03} \\
\hline \multirow{3}{*}{$\begin{array}{l}\text { Longitud de la hoja } \\
\qquad(\mathrm{cm})\end{array}$} & Lluvia & $85,6 \mathrm{~d}$ & $87,3 \mathrm{c}$ & $93,30 b$ & $96,7 \mathrm{c}$ \\
\hline & Seca & $89,2 \mathrm{~d}$ & $97,5 \mathrm{c}$ & $97,70 \mathrm{~b}$ & $101,6 a$ \\
\hline & $\pm \mathrm{ES}$ & \multicolumn{4}{|c|}{0,51} \\
\hline \multirow{3}{*}{$\begin{array}{l}\text { Número de hojas } \\
\text { (U) }\end{array}$} & Lluvia & $11,4 \mathrm{c}$ & $12,9 \mathrm{c}$ & $15,4 b$ & $18,5 b$ \\
\hline & Seca & $12,3 \mathrm{~d}$ & $12,9 \mathrm{c}$ & $13, \mathrm{~b}$ & $21,3 a$ \\
\hline & $\pm \mathrm{ES}$ & \multicolumn{4}{|c|}{0,14} \\
\hline \multirow[t]{3}{*}{ Hojas verdes (\%) } & Lluvia & $31,3 b$ & $51,59 \mathrm{a}$ & $19,5 \mathrm{bc}$ & $15,8 \mathrm{~d}$ \\
\hline & Seca & $28,25 \mathrm{bc}$ & $32,30 \mathrm{c}$ & $35,4 b$ & $20,5 b c$ \\
\hline & $\pm \mathrm{ES}$ & \multicolumn{4}{|c|}{0,05} \\
\hline \multirow[t]{3}{*}{ Tallos verdes $(\%)$} & Lluvia & $68,3 \mathrm{~cd}$ & $77,04 \mathrm{~b}$ & $80,6 b$ & $97,3 \mathrm{a}$ \\
\hline & Seca & $65,4 \mathrm{e}$ & $70,20 \mathrm{~d}$ & $72,5 \mathrm{~cd}$ & $75,9 b c$ \\
\hline & $\pm \mathrm{ES}$ & \multicolumn{4}{|c|}{0,08} \\
\hline
\end{tabular}

a, b, c, d,e Letras diferentes en cada variable difieren entre sí según Keuls (1952). Nivel de significancia al p $\leq 0,001$. ES \pm : Error estándar / Different letters in each variable differ from one another according to Keuls (1952). Significance level at $\mathrm{p} \leq 0.001$. ES: Standard error.

La longitud de la hoja se incrementó paulatinamente en función de la edad, y las mayores dimensiones se observaron a la edad de 120 días de la época poco lluviosa, que difirió significativamente del resto de los promedios propios en esta estación y en la estación de lluvias, las estaciones climáticas no se diferenciaron en las dimensiones de la hoja en las edades de 60, 80 y 100 días, pero sí a los 120, donde el menor ( $\leq \leq 0,001)$ promedio se obtuvo en la estación de lluvias. Efecto similar se manifestó en el número de hojas por planta, pero en esta variable, las estaciones climáticas difirieron $(\mathrm{p} \leq 0,001)$ a la edad de 60 y 120 días, respectivamente, en esta última se registró el mayor ( $\mathrm{p} \leq 0,001)$ número de hojas en la estación poco lluviosa, y el valor inferior $(\mathrm{p} \leq 0,001)$ se obtuvo a la edad de 60 días en la estación lluviosa.

El porcentaje de hojas verdes tuvo un comportamiento variable por el efecto de la interacción, a los 80 días en las lluvias se obtuvo el mayor valor $(\mathrm{p} \leq 0,001)$, el cual difirió con el resto de los promedios de cada edad en esa 
estación climática, y con los promedios de las edades en la estación poco lluviosa. El valor más bajo ( $\mathrm{p} \leq 0,001)$ se obtuvo a las edades de 120 días en la estación de lluvias, y de igual forma, difirió con el resto de los promedios en ambas estaciones climáticas. Las medias de las edades de 60 y 120 días en la estación poco lluviosa, no difirieron de la media de la edad de 100 días en la lluvia, pero sí presentaron diferencias significativas con los valores máximos y mínimos ( $\mathrm{p} \leq 0,001)$, y con el promedio de la edad de 80 días en la estación lluviosa, y este a su vez, con el promedio de la edad de 60 días en lluvias y con el de los 100 días en pocas lluvias.

El porcentaje de tallos verdes, fue en aumento en la medida que se incrementó la edad de rebrote en ambas estaciones climáticas, registrándose el valor significativamente superior a la edad de 120 días en las lluvias, y el valor inferior de forma significativa a los 60 días en la estación de pocas precipitaciones. Ambos valores difirieron, entre ellos y con el resto de los promedios de las restantes edades de rebrote en los dos períodos climáticos, las edades de 60 días en las lluvias y 100 días en pocas lluvias, no difirieron estadísticamente, al igual que los valores correspondientes a las edades de 80 y 100 días en las lluvias, pero estos dos grupos de valores sí se diferenciaron estadísticamente entre ellos y con el resto de las edades en los dos períodos climáticos.

\section{Discusión}

El rendimiento promedio fue superior en la estación lluviosa, lo que indica el efecto positivo que tienen las lluvias en la productividad de las plantas (Cuadro 2). En esta estación climática las temperaturas fueron más altas, hay mayor humedad del suelo y duración del día, efectos que propician que se exprese el potencial de crecimiento y mayor acumulación de biomasa (Rodríguez et al., 2011).

En la estación lluviosa en el Valle del Cauto, Ramírez (2010) correlacionó el rendimiento de la variedad Cuba CT-169 con algunas variables climáticas, y las precipitaciones transversalizaron el comportamiento productivo de la variedad evaluada, mientras que, en el período poco lluvioso, fueron las temperaturas (mínima, media y máxima) $(\leq 0,85)$, más que las precipitaciones $\left(R^{2} \leq 0,65\right)$, las que determinaron la productividad, de lo que se infiere que, las nuevas variedades en la época poco lluviosa respondieron favorablemente ante el estrés hídrico. La baja productividad en el período poco lluvioso, y la baja eficiencia en la utilización del agua para la producción de forraje, fue relacionada por Ramírez (2010), este criterio coincidió con el expuesto por Herrera y Ramos (2006) cuando evaluaron al Napier y King Grass, y quizás estuvo manifiesto en las condiciones experimentales en las que se desarrolló el presente estudio, sin embargo, es necesario demostrarlo en estudios posteriores.

En el occidente de Cuba en la estación de lluvias, las temperaturas fueron las que definieron el comportamiento productivo en $C$. dactylon coast cross, Panicum maximum, Cenchrus ciliaris y nuevos clones de $C$. purpureus obtenidos por cultivos de tejidos a partir del CT-115. En la estación de pocas precipitaciones, la temperatura mínima $\left(\leq 20^{\circ} \mathrm{C}\right)$ influyó en el rendimiento, concluyendo que las mayores fluctuaciones de las temperaturas en el período poco lluvioso pudieron explicar las altas correlaciones, tanto positivas como negativas (Herrera, 1981; Álvarez et al., 2013).

El efecto de las variables climáticas que, en el occidente de Cuba modificaron el comportamiento productivo de las variedades referidas por Herrera (1981) y Álvarez et al. (2013), no coincidieron con las referidas por Ramírez (2010), quién describió durante el período experimental las relaciones con las temperaturas, señalando que fueron variables y bajas, y sus valores promedio máximos estuvieron entre 30,6 y $33{ }^{\circ} \mathrm{C}$, que coincidieron con los registros del período experimental del presente estudio, y es este rango considerado como óptimo para el desarrollo de las gramíneas tropicales, lo que evidencia que, el comportamiento climático y sus variables, en ocasiones muy específicas y características de cada región, definen la productividad de las pasturas tropicales, por lo que, no deben extrapolarse tecnologías ni sistemas de manejo si no se tienen en cuentas las características regionales en conjunto y su efecto en la productividad de las plantas. 
Los resultados expuestos en el Cuadro 2, superan los obtenidos por Álvarez et al. (2013) en ambas épocas climáticas, y los referidos por Martínez et al. (2010) en el período lluvioso con la aplicación de fertilización química en la evaluación de la curva de acumulación de biomasa de CT-169, OM-22 y King grass. También superaron a los obtenidos por García et al. (2014) en ambas estaciones climáticas y en condiciones de secano en un suelo pardo de Las Tunas, en cuatro cultivares de Cenchrus. Valles-de-la-Mora et al. (2016), también obtuvieron rendimientos inferiores a los reflejados en el Cuadro 3, cuando evaluaron diez variedades de pastos tropicales en diferentes edades de rebrote, lo que les confiere, a las nuevas variedades, fortaleza para constituir una fuente de biomasa que tolera el estrés por sequía, con adecuados niveles productivos en la época seca del Valle del Cauto.

Las variedades en estudio superaron los rendimientos que se obtuvieron con ellas en el occidente de Cuba (Herrera, 2009), y como se mencionó con anterioridad, es esta región del país beneficiada con respecto a los promedios máximos de precipitaciones y menos exigencia por parte de la temperatura máxima, para el desarrollo de las plantas. Esta respuesta positiva de las nuevas variedades en ambas estaciones climáticas, le confiere atributos productivos estables, que es precisamente el interés de la ciencia agropecuaria en Cuba y gran parte de Latinoamérica y el Caribe.

Las variedades CT-601, CT-603 y CT-605, pueden producir respectivamente, en un año con cortes cada 60 días 14,$5 ; 16,5$ y 19,8 t/MS/ha, a los $80,22,5 ; 32,8$ y 28,5 t/MS/ha, mientras que, a los 100 días, 27,8; 39,2 y 48,4 t/MS/ ha, y a los 120 días, 36,8; 47,1 y 85,2 t/MS/ha. Estos valores superan los referidos por Duke (1981), quien encontró rangos productivos que oscilaron entre 20 y 85 t/MS/ha/año en diferentes regiones del mundo, lo que denota la plasticidad de las nuevas variedades ante las exigencias climática del Valle del Cauto.

Los rendimientos de CT-605 correspondientes a un año con cortes a los 120 días de edad, superaron a los obtenidos en Australia (79 t/MS/ha/año), Brasil (66 t/MS/ha/año), Costa Rica (58 t/MS/ha/año), Pakistán (64 t/ MS/ha/año), Puerto Rico (84 t/MS/ha/año) y Tailandia (76 t/MS/ha/año), referidos por Martínez et al. (2010), y se igualan a los de El Salvador (85 t/MS/ha/año). Los rendimientos obtenidos para CT-603 superaron a los comunicados para Uganda (30 t/MS/ha/año) y Kenia (48 t/MS/ha/año); sin embargo, son inferiores a los valores de rendimiento comunicados por Duke (1983) en regiones climáticas semejantes a la de Cuba, donde se contabilizaron rendimientos de 27,3 y 37,1 t/MS/ha para intervalos de rebrote entre 45 y 60 días, no obstante, estas son frecuencias de corte que generan gastos de mantenimiento por el empleo de fertilización y riego, porque en ambas edades la planta no ha concluido su desarrollo, y las reservas acumuladas no son suficientes para garantizar un rebrote vigoroso que permita la persistencia del cultivo.

Los resultados de las nuevas variedades, reflejan las potencialidades productivas en cuanto a rendimiento se refiere cuando interactuaron las edades de rebrote, las variedades y las estaciones climáticas que caracterizan al Valle del Cauto. Las diferencias radican principalmente en la variabilidad climática de cada región donde se desarrollaron los estudios citados, así, Batista (2006) hizo referencia a la susceptibilidad genética a los estímulos climáticos, donde enfatizó que determinados genes se activan ante estímulos precisos, y esto determina, por supuesto, la evolución y respuesta en estructura y productividad de los cultivos, por eso se deben esperar modificaciones agronómicas y morfológicas cuando interactúen la variedad, la edad de rebrote y la estación climática como fuente de variación en un estudio agronómico de gramíneas tropicales

Para la interacción edad de rebrote con variedad en el comportamiento de la cantidad de hojas por planta (Figura 2), se le atribuye a las nuevas variedades una importancia preponderante, porque aún a la edad de 120 días presentaron un número de hojas cercano a 20 , se puede intuir que el proceso de senescencia afecta menos a CT603, y en mayor grado a CT-601 y CT-605, pero de igual forma posibilita su utilización hasta los 120 días de edad, y este es un resultado de gran impacto, ya que, las hojas constituyen la base fundamental para la alimentación del ganado, en ellas el animal encuentra los elementos nutritivos necesarios para su crecimiento y desarrollo (Álvarez et al., 2016). El número de hojas que presente una planta, especialmente las gramíneas, les permitirá alcanzar una productividad mayor, con mejor calidad química (Ledea, 2016), por la alta capacidad fotosintética que le posibilita 
alcanzar el número de hojas (Fortes, 2012), y por el aporte que hace este órgano al incremento del área foliar (Igarza, 2007). Los promedios que se refieren fueron inferiores a los referidos por Ramírez (2010) en condiciones de pre-montaña y superiores a los obtenidos por Díaz (2007) en un suelo Fluvisol del Valle del Cauto, las diferencias están dadas principalmente, por el clima que impera en cada ecosistema (pre-montaña y llano) (ONEI, 2014) y que influye la productividad de los pastos.

Los valores reflejados para el ancho de la hoja en las variedades en estudio (Figura 4), fueron semejantes a los publicados por Díaz (2007) en condiciones de secano, superiores a los emitidos por Arias (2012) con la aplicación de riego, y menores que los referidos por Ramírez (2010). Estas diferencias se debieron principalmente a las condiciones climáticas que imperaron en cada etapa y ecosistema experimental (Igarza, 2007; Ramírez-dela-Ribera, 2010).

Para el ancho del tallo (Figura 5), los valores obtenidos fueron inferiores a los encontrados por Ramírez (2010), y superiores a los emitidos por Díaz (2007) en las edades de 60, 80 y 100 días, e inferiores para los 120 días de edad, ya que, a esa edad, este comportamiento de superioridad se invirtió, donde refirieron los autores que las variedades en estudio alcanzaron $326 \mathrm{~mm}$ de diámetro. El engrosamiento del tallo se relaciona con el proceso de crecimiento y maduración del órgano, y está en correspondencia con el desarrollo foliar de la planta, gran parte del incremento del grosor de este órgano se debe a la acumulación de carbohidratos solubles y estructurales (Valladares et al., 2015), que son utilizados por la planta para el proceso de rebrote (Fortes, 2012), cuando el proceso de envejecimiento tisular se encuentra avanzado.

Para el porcentaje de tallos verdes (Figura 6), la acumulación de tallos es característico de las gramíneas tropicales, debido al rápido crecimiento y maduración que identifica a este género (Fortes, 2012), comportamiento que coincidió con el obtenido por Ramírez (2010), Arias (2012), Fortes (2012) y Fernández et al. (2015). En el criterio de Fortes (2012), la acumulación de tallos contribuye a que se incremente la producción de MS, por lo que, recomienda utilizar la proporción hoja/tallo cuando esta no se incremente por encima de un $70 \%$ para los tallos, ya que la MS obtenida a las edades donde se rompe esta relación es de poca utilidad para el animal, aunque numéricamente sea viable. El porcentaje de tallos va a tener una importante contribución a ese rendimiento de MS, sin embargo, esta va a poseer una baja calidad química, caracterizada por presentar carbohidratos estructurales de forma mayoritaria (Ledea, 2016).

En el oriente de Cuba, diversos autores corroboraron, al evaluar gramíneas tropicales del género Cenchrus, que el desarrollo de los tallos fue superior al de las hojas a medida que se incrementó la edad del cultivo (Ramírez, 2010; Arias, 2012; Verdecia, 2015). Este fenómeno puede estar dado, según Hidalgo (2003), por las respuestas de las plantas ante las condiciones climáticas, que se refleja en la dinámica de crecimiento y maduración celular, y está predispuesto por la capacidad de almacenamiento de sustancias de reserva para el engrosamiento y mayor cantidad de tallos (Medina et al., 2013), y esta variable no hace ninguna contribución a la variabilidad de la varianza (Castañeda et al., 2015).

Mediante análisis de componentes principales, Castañeda et al. (2015) obtuvieron que la hojosidad, variable que contribuye con la representación porcentual de las hojas vedes (Figura 7) con respecto al resto de los órganos, ayudó en la estación lluviosa a explicar el $41 \%$ de la varianza extraída en conjunto con el rendimiento, sugiriendo este resultado, que la cantidad de hojas junto al rendimiento explican mejor la variabilidad en el occidente de Cuba. En el presente estudio esta variable (porcentaje de hojas verdes), mostró el patrón de comportamiento de las gramíneas tropicales. Los valores que se obtuvieron para CT-601 y CT-603, no superaron los referidos por García et al. (2014) en el período poco lluvioso para cuatro variedades de gramíneas tropicales, sin embargo, CT-605 sí los superó en ambas estaciones climáticas, esto denota que cada variedad responde a partir de mecanismos intrínsecos a respuestas externas, determinado quizás por la genética.

Cuando la interacción variedad con estación climática (Figura 8) afectó el porcentaje de hojas verdes, el comportamiento mostrado no coincidió con el descrito por Herrera (1981), quien aseveró que, esta variable 
disminuye en función del tiempo y número de cortes, debido principalmente según la acumulación de material muerto, pero no tuvieron en cuenta el efecto de la estación climática en este proceso. El número de hojas, muy relacionado con el porcentaje de hojas verdes, es un carácter constante poco influenciado por el efecto climático (Nozzolini, 1963), criterio contradictorio con los principios fisiológicos de las plantas (Zarra y Revilla, 2000). De igual manera, sucede con el porcentaje de tallos verdes (Figura 9), donde también afectó esta interacción, coincidiendo con los resultados obtenidos por Fernández (1998) en el Valle del Cauto, refiriendo este autor que los mayores porcentajes de tallos en Brachiaria radicans se concentraron en la estación poco lluviosa. Ramírez (2010) obtuvo promedios inferiores en cuatro gramíneas tropicales a los reflejados en la Figura 7 en condiciones del Valle del Cauto, lo que sugiere una alta velocidad de crecimiento y madurez por parte de las nuevas variedades evaluadas, Arias (2012) obtuvo velocidades de crecimiento absolutas de $1 \mathrm{~cm} /$ día.

En el Cuadro 3 el efecto de la interacción estación climática con edad de rebrote, el cual afectó algunas variables agronómicas, entre ellas el grosor del tallo. El comportamiento mostrado por esta variable se debe a que, la planta, para la edad de 120 días en lluvias, posee un avanzado estado de lignificación, y comienzan a enviar los compuestos de reservas para las raíces y otros órganos (Arias, 2012), para poder ser utilizados, según Fortes (2012), en el brote de hijos basales, en ramificaciones y prepararse para el rebrote después de cortadas. Los resultados obtenidos fueron inferiores a los emitidos por Arias (2012) para la edad de 80 días, solo en la estación de lluvias, y superiores en todas las edades para el período seco. Valores superiores fueron obtenidos por Fernández et al. (2015) para todas las edades contempladas en este estudio, pero el suelo donde estos autores desarrollaron su estudio fue diferente al que se utilizó en este experimento, y este le brindó a las plantas los nutrimentos necesarios para que lograran grosores de tallos mayores, por el acúmulo de carbohidratos solubles.

La longitud de la hoja también se afectó por esta interacción. Los valores de la estación poco lluviosa fueron superiores a los reportados por Arias (2012) en las edades de 60 y 120 días con la utilización de riego, e inferiores para la edad de 100 días, lo que denota la eficiencia de utilización del agua por parte de las variedades y el efecto de la edad de rebrote en combinación con otros efectos. En condiciones de pre-montaña, en esta misma estación climática, Ramírez (2010) refirió valores superiores para la edad de 100 días, por las diferencias climáticas de los ecosistemas en los que se desarrollaron los experimentos. Las dimensiones de las hojas en todas las edades evaluadas en la estación lluviosa, fueron inferiores a la reportada por varios autores (Herrera y Martínez, 2006; Fernández et al., 2015), sin embargo, para la edad de 100 y 120 días, mostraron valores superiores.

Con el alargamiento de las hojas se asegura mayor fotosíntesis por unidad de superficie, además de incrementar el área foliar, todo parece indicar que este es el mecanismo de compensación que utilizaron las gramíneas en el Valle del Cauto para el exceso de incidencia de luz solar (horas/luz) en la estación de lluvias, lo que denota una adaptación que favorece la persistencia del cultivo y puede favorecer su valor nutritivo.

El número de hojas tuvo un comportamiento similar. Al respecto, Herrera (2008) indicó que, el incremento del número de hojas propicia la probabilidad de eficiencia fotosintética y con ello, mayor posibilidad de producción de sustancias para el crecimiento, con la acumulación de sustancias de reserva para el rebrote. Esto también propicia mayor cantidad de nutrientes en las hojas, y posibilita un mayor consumo por el animal. En este estudio, la estación climática afectó más la morfología de la hoja y de la planta, que la edad de rebrote. En el Valle del Cauto, Fernández et al. (2015), obtuvieron comportamientos inferiores para la variable en cuestión, al evaluar dos cultivares de $C$. purpureus, al finalizar las lluvias sin riego ni fertilización orgánica, respuesta que pudo estar asociada al efecto del período de transición de los períodos climáticos, que lo caracterizan otros componentes climáticos.

Para el porcentaje de hojas verdes, las variedades de Cenchrus Taiwan 8001-4 y Taiwan 144 en condiciones de secano, se encontraron que a partir de los 75 días, se deprimió considerablemente (Ibarra y León, 2001), efecto que comenzó en las nuevas variedades de este estudio a los 80 días. Sin embargo, Fernández (1998) señaló valores superiores a los 49 días de edad en Brachiaria radicans, B. purpurascens y B. humidicola en el Valle del Cauto. resultados superiores a los observados en este estudio los obtuvieron García et al. (2014), cuando evaluaron el 
potencial forrajero de cuatro cultivares de C. purpureus en un suelo pardo de Las Tunas, con edades de 60 días en época de lluvia y 90 días en estación seca. Sin embargo, Cordoví et al. (2013) obtuvieron resultados inferiores cuando caracterizaron especies arbustivas y forrajeras en el clima semiárido de Mozambique.

La planta en la estación de precipitaciones puede reducir su crecimiento y las dimensiones de la hoja, lo que puede interpretarse en el término de las ventajas que presentan las hojas pequeñas por mantener una temperatura adecuada en ambientes cálidos, ya que, un menor tamaño de hoja reduce la resistencia de la capa de frontera y ayuda a mantener favorable la temperatura de la misma (Pérez et al., 2004). Además, permite mantener una elevada eficacia en el uso del agua en condiciones de poca disponibilidad hídrica o baja conductancia estomática, este mecanismo refleja modificaciones fisiológicas que adoptan estos cultivos en ecosistemas frágiles y degradados, lo cual coincide con el criterio de Díaz (2007), quien señaló que este comportamiento es una expresión adaptativa de las nuevas variedades a condiciones de intensa sequía, mecanismo que pudieron desarrollar las plantas en el presente estudio.

El comportamiento que mostraron las variedades en ambas estaciones climáticas, lo refirió Álvarez (2009) como un mecanismo de adaptación a la adversidad del clima y vigor de la planta. Este mismo autor obtuvo $\mathrm{r}$ de $-0,11$ entre porcentaje de hojas y el largo de las mismas en la lluvia, y -0,0 en la seca, de lo que se concluye que, la estación climática altera la correlación entre los componentes agromorfológicos por la variabilidad y particularidad del clima para cada período climático.

El porcentaje de tallos verdes (Cuadro 3) coincidió con los valores obtenidos por Díaz (2007) en la estación poco lluviosa; en la estación lluviosa este autor obtuvo valores superiores al $35 \%$.

En el contenido de hojas en King grass, CT-16 y CT-44, Herrera y Martínez (2006) encontraron valores inferiores. Sin embargo, Machado y Machado (2009) obtuvieron valores entre 59 y $62 \%$ en ocho variedades de Pennisetum purpureum en Matanzas, y Roche y Hernández (1993) coincidieron en encontrar mayor porcentaje de hojas en seca (59-72\%) con relación a la lluvia (48-55\%) en once somaclones de Pennisetum purpureum, aunque esos altos valores estuvieron influidos por las condiciones de riego y fertilización aplicadas en ese estudio.

\section{Conclusiones}

Las nuevas variedades presentaron una adecuada respuesta productiva, y características como la depresión del comportamiento productivo, y las modificaciones agronómicas, influidas por el efecto de la interacción estación climática con edad de rebrote y variedad, no constituyeron una limitante para su utilización.

\section{Literatura citada}

Almaguer, R. 2012. Evaluación del establecimiento de variedades de Pennisetum purpureum resistentes a la sequía en condiciones de premontaña. Tesis Lic., Universidad de Granma, Bayamo, CUB.

Álvarez, Y. 2009. Evaluación inicial de nuevas variedades de Pennisetum purpureum con tolerancia a la salinidad en el Valle del Cauto. Tesis MSc., Universidad de Granma, Bayamo, CUB.

Álvarez, G.R., A.R. García, R.R. Cabezas, M.C. Samaniego, T.E. Jacho, C.M. Rivera, E. Chacón, y J.L. Ramírez. 2016. Asociación del pasto Cenchrus purpureus vc Morado con dos leguminosas a diferentes edades de corte. REDVET 17(6):1-9. http://www.veterinaria.org/revistas/redvet/n060616/061603.pdf

Álvarez, A., S.R. Herrera, L. Díaz, y A. Noda. 2013. Influencia de las precipitaciones y la temperatura en la producción de biomasa de clones de Pennisetum purpureum. Rev. Cub. Cienc. Agríc. 47:413-417. 
Arias, R.C. 2012. Frecuencias de corte en cultivares promisorios de Pennisetum purpureum resistentes a la sequía con riego y fertilización orgánica. Tesis MSc., Universidad de Granma, Bayamo, CUB.

Bartlett, M. 1937. Properties of sufficiency and statistical tests. Proc. Royal Soc. London. Ser. A, Mathemat. Phys. Sci. 160:268282.

Barranco, G., y L.R. Díaz. 1989. Clima. En: E.A. Sánchez-Herrero et al., editores, Nuevo Atlas Nacional de Cuba. Instituto de Geografía de la Academia de Ciencias de Cuba, e Instituto Cubano de Geodesia y Cartografía, CUB. p. 15-20.

Batista, E.L. 2006. Evaluación morfoagronómica de variedades de cebolla (Allium cepa L.) en diferentes localidades de la región oriental cubana. Tesis Dr., Instituto de Ciencias Agrícola, La Habana, CUB.

Castañeda, L., Y. Olivera, y H.B. Wencomo. 2015. Selección de accesiones de Pennisetum purpureum para fomentar sistemas de alimentación ganadera. Pastos y Forrajes 38:170-175.

Chemisquy, M.A., M.L. Giusani, M.A. Scataglini, A.E. Kellog, and O. Morrone 2010. Phylogenetic studies favour the unification of Pennisetum, Cenchrus and Odontelytrum (Poaceae): a combined nuclear, plastid and morphological analysis, and nomenclatural combinations in Cenchrus. Ann. Bot. 106:107-130. doi:10.1093/aob/mcq090

Cordoví, E., J.V. Ray, O. Tamele, S. Nhantumbo, y A. Chimbalambala. 2013. Caracterización de especies arbóreas y arbustivas forrajeras en clima semiárido del sur de Mozambique. Pastos y Forrajes 36:434-439.

Cruz, J.M., J.V. Ray, J.L. Ledea, y R.C. Arias. 2017. Establecimiento de nuevas variedades de Cenchrus purpureus en un ecosistema frágil del Valle del Cauto, Granma. Rev. Prod. Anim. 29(3):29-35.

Díaz, D. 2007. Evaluación agronómica de nuevas variedades Pennisetum purpureum en condiciones de sequía el Valle del Cauto. Tesis MSc., Universidad de Matanzas, CUB.

Duke, J.A. 1981. The gene revolution. In: Matews et al., editors, Office of Technology Assessment, Background papers for innovative biological technologies for lesser-developed countries. USGPO, WA, USA. p. 89-150.

Duke, J.A. 1983. Handbook of energy crops. NewCROP, West Lafayette, IN, USA. https://www.hort.purdue.edu/newcrop/ duke_energy/dukeindex.html (accessed 3 Nov. 2015)

Fernández, J.L. 1998. Determinación de la productividad de tres especies del género Brachiaria en vertisuelo del valle del cauto. Tesis MSc., Universidad de Granma, Bayamo, CUB.

Fernández, M.J., I.M Viamonte, N. Fonseca, y A. Ramírez. 2015. Evaluación de dos cultivares de Pennisetum purpureum tolerantes a la sequía en la región de Cauto Cristo, Granma, Cuba. Cienc. Tecnol. Ganadera 9(1):23-29.

Fortes, D. 2012. Comportamiento de algunos indicadores morfofisiológicos y de calidad de Pennisetum purpureumvc. Cuba CT-115 utilizado como banco de biomasa. Tesis Dr., Instituto de Ciencia Animal, CUB.

García, L.M., A.R. Mesa, y M. Hernández. 2014. Potencial forrajero de cuatro cultivares de Pennisetum purpureum en un suelo Pardo de Las Tunas. Pastos y Forrajes 37:413-419.

Hernández, A., J.M. Pérez, D. Bosch, L. Rivero, y I. Camacho. 2015. Nueva versión de la clasificación genética de los suelos de Cuba. Instituto de Suelos. Ministerio de la Agricultura, y AGRINFOR, La Habana, CUB.

Herrera, R.S. 1981. Influencia de la fertilización nitrogenada y edad de rebrote en la calidad del pasto bermuda cruzada (Cynodon dactylon vc. Coast cross). Tesis Dr., Instituto de Ciencia Animal, La Habana, CUB.

Herrera, R.S. 2000. Obtención de plántulas de Pennisetum purpureum con resistencia a la sequía y salinidad mediante técnicas biotecnológicas. Informe final de proyecto. CITMA-ICA, La Habana, CUB.

Herrera, R.S. 2008. Principios básicos de fisiología vegetal. En: Martínez et al., editores. Pastos tropicales, principios generales agrotecnia y producción de materia seca. EDICA y FIRA, MEX. p 1-5. 
Herrera, S.R. 2009. Mejoramiento de Pennisetum purpureum en Cuba. Rev. Cub. Cienc. Agríc. 43:345-349.

Herrera, R.S., Z. Chaplé A.M. Cruz, A. Romero, y M. García. 2003. Obtención de plántulas de Pennisetum purpureum resistentes a la sequía y salinidad. Nota técnica. Rev. Cub. Cienc. Agríc. 37:189-191.

Herrera, R.S., R. Cruz, y R.O. Martínez. 1993. Estudio de mutantes de King grass (Pennisetum purpureum sp) obtenidos mediante técnicas nucleares y mutágenos químicos. II. Indicadores morfológicos. Rev. Cub. Cienc. Agríc. 27:213-218.

Herrera, R.S., y N. Ramos. 2006. Factores que influyen en la producción de biomasa y calidad. En: R.S. Herrera et al., editores, Pennisetum purpureum para la ganadería tropical. Instituto de Ciencia Animal, La Habana, CUB. p 25-30.

Herrera, R.S., y R.O. Martínez. 2006. Mejoramiento genético por vías no clásicas. En: R.S. Herrera et al., editores, Pennisetum purpureum para la ganadería tropical. Instituto de Ciencia Animal, La Habana, CUB. p. 79-94.

Hidalgo, R. 2003. Variabilidad genética y caracterización de especies vegetales. En: T.L. Franco, y R. Hidalgo, editores, Análisis estadístico de datos de caracterización morfológica de recursos fitogenéticos. Boletín técnico IPGRI No. 8. Instituto Internacional de Recursos Fitogenéticos, Cali, COL. p. 2-26.

Ibarra, G., y J. León. 2001. Comportamiento bajo corte de dos variedades de Pennisetum purpureum: Taiwan 801-4 y Taiwan 144 en condiciones de secano. Rev. Prod. Anim.13(1):31-34.

Igarza, A. 2007. Caracterización ecofisiológica de Pennisetum Cuba CT-115 bajo las condiciones edafoclimáticas de una zona del Valle del Cauto. Tesis MSc., Universidad de Granma, CUB.

Keuls, M. 1952. The use of the 'studentized range' in connection with an analysis of variance. Euphytica 1:112-122. doi:10.1007/ BF01908269

Ledea, J.L. 2016. Caracterización químico nutritiva de nuevas variedades de Cenchrus purpureus tolerantes a la sequía en el Valle del Cauto. Tesis en MSc., Universidad de Granma, CUB.

Ledea, J.L., D.G. Benítez, R.C. Arias, y A. Guerra. 2017. Comportamiento agronómico de cultivares de Cenchrus purpureus tolerantes a la salinidad. Rev. Prod. Anim. 29(3):18-28.

Machado, R., y H. Machado. 1988. Estimación de la adaptabilidad y estabilidad de variedades de Pennisetum purpureum en diferentes condiciones ambientales. Pastos y Forrajes 11:213-219.

Martínez, R.O., R. Tuero, V. Torres, y R.S. Herrera. 2010. Modelos de acumulación de biomasa y calidad en las variedades de hierba elefante, Cuba CT-169, OM-22 y King grass durante la estación lluviosa en el occidente de Cuba. Rev. Cub. Cienc. Agríc. 44:189-194.

Massey, F.J. 1951. The Kolmogorov-Smirnov test for goodness of fit. J. Am. Stat. Assoc. 46:68-78. doi:10.2307/2280095

Medina, J., R. Pinto., L. Cárdenas., F. Guevara., H. Gómez, y A. Hernández. 2013. Producción y calidad del pasto maralfalfa (Pennisetum sp.) durante la época seca. En: R.S. Herrera et al., editores, Memorias IV Congreso Internacional de Producción Animal Tropical. Instituto de Ciencia Animal, La Habana, CUB. p. 271-275.

Nozzolini, V. 1963. Il numero delle foglie quale índice della lunghezza del periode vegetative nel mais. Maydica 8:39-72.

ONEI (Oficina Nacional de Estadística e Información). 2014. Anuario estadístico de Cuba 2014. Capítulo I. Territorio. ONEI, CUB. http://www.onei.cu/aec2014/00\%20Anuario\%20Estadistico\%202014.pdf (consultado 12 ene. 2015).

ONEI (Oficina Nacional de Estadística e Información). 2015. Panorama ambiental. Lluvia total anual por provincias. ONEI, CUB. http://www.onei.cu/publicaciones/04industria/medioambientecifras/medioamb2014.pdf (consultado 25 oct. 2017).

Pérez, J.A., E. García, J.F. Enríquez, A.R. Quero, J. Pérez, y A. Hernández. 2004. Análisis de crecimiento, área foliar específica y concentración de nitrógeno en hojas de pasto "mulato" (Brachiaria híbrido, cv.). Téc. Pecu. Méx. 42:447-458. 
Ray, J., R.S. Herrera, D. Benítez, D. Díaz, R. Arias. 2016. Multivariate analysis of the agronomic performance and forage quality of new clones of Pennisetum purpureum drought tolerant in Valle del Cauto, Cuba. Cub. J. Agric. Sci. 50:639-648.

Ramírez, A. 2010. Caracterización y tipificación de las fincas ganaderas en ecosistemas montañosos del macizo Sierra Maestra. Tesis Dr., Instituto de Ciencia Animal, CUB.

Ramírez-de-la-Rivera, J.L. 2010. Rendimiento y calidad de cinco gramíneas en el Valle del Cauto. Tesis Dr., Instituto de Ciencia Animal. Mayabeque, CUB.

Roche, R., y F. Hernández. 2009. Estudio comparativo de somaclones de King grass (Pennisetum purpureum) con riego. Pastos y Forrajes 16:138-145.

Rodríguez, L., V. Torres., R.O. Martínez., O. Jay., A.C. Noda, and M. Herrera. 2011. Models to estimate the growth dynamics of Pennisetum purpureum cv. Cuba CT-169. Cub. J. Agric. Sci. 45: 349-354.

Valles-de-la-Mora, B., E. Castillo, y H. Bernal. 2016. Rendimiento y degradabilidad ruminal de la materia seca y energía de diez pastos tropicales cosechados a cuatro edades. Rev. Mex. Cienci. Pecu. 7:141-158.

Valladares, F., I. Varela, L. Hernández, J. Montalván, y M. Padrón. 2015. Producción de la materia seca en tallos y hojas de caña de azúcar, según épocas de plantación y edades de corte. Agrisost. 21(2):1-11.

Verdecia, D. 2015. Calidad nutritiva de árboles, arbustos y leguminosas volubles, con énfasis en su contenido de metabolitos secundarios. Tesis Dr., Instituto de Ciencia Animal, CUB.

Zarra, I., y G. Revilla. 2000. Fundamentos de fisiología vegetal. $2^{\text {da }}$ ed. McGraw-Hill-Interamericana, Madrid, ESP. 